\title{
Benign intrapulmonary teratoma: Report of a case
}

\author{
Mehmet Nesimi Eren, Akın Eraslan Balci, and Şevval Eren, Diyarbakır, Turkey
}

A lthough intrathoracic teratomas are frequent, benign intrapulmonary teratomas seldomly occur. Only 37 cases have been reported so far. It is known that these tumors originate from the third pharyngeal sac. Teratomas occur with the same incidence in men and women.

These tumors generally become manifest with their complications such as lung abscess, bronchiectasis, empyema, and hemoptysis. Preoperative diagnoses are usually inaccurate. We review the literature and report a case.

\section{Case Report}

An 18-year-old patient presented with a 2-month history of left side pain, cough, expectoration, and fever. The patient had been given nonspecific treatment a week before. Later she was hospitalized with a prediagnosis of lung abscess in another clinic. Conservative treatment for lung abscess, lung biopsy, and antibiotic treatment according to the biopsy yielded no result. The patient was referred to us with a diagnosis of chronic lung abscess.

There was a cavitary area measuring $61 \times 72 \mathrm{~mm}$ near the middle-lower zone on the chest radiograph (Figure 1, $A$ and $B$ ). A round hypodense cystic mass was observed on thorax computed tomography (Figure 2). Adjacent lung collapse and bronchiectasis were present.

The diagnosis was cystic lung abscess. The patient refused bronchoscopy. Medical therapy was continued but no improvement was observed; thus we decided to operate. Left anterolateral thoracotomy was performed. After freeing the lung, it was observed that the left upper lobe was nonfunctioning and destroyed. Additionally, a mass measuring $5 \times 5 \times 4 \mathrm{~cm}$ covered with hair was seen in the lung. Upper lobectomy was performed (Figure 3 ).

On macroscopic examination, the specimen measured $6 \times 4 \times$ $4 \mathrm{~cm}$ and had a grayish-white outer surface. At cut section, it was filled a dense fluid. Wall thickness of the mass was 0.5 to $1 \mathrm{~cm}$.

Microscopically, the lumen was lined with stratified epithelium. On the fibrocollagen stroma, under the epithelium, there were hair follicles and sebaceous and eccrine glands that made another wall. Figure 4 shows stratified epithelium, hair follicles, and glands.

\footnotetext{
From the Department of Thoracic and Cardiovascular Surgery, Dicle University School of Medicine, Diyarbakır, Turkey.

Received for publication Nov 15, 2002; accepted for publication Nov 25, 2002.

Address for reprints: Akın Eraslan Balci, Firat University School of Medicine, Department of Thoracic Surgery, 23100, Elazig, Turkey (E-mail: abalci@firat.edu.tr).

J Thorac Cardiovasc Surg 2003;126:855-7

Copyright (C) 2003 by The American Association for Thoracic Surgery $0022-5223 / 2003 \$ 30.00+0$

doi:10.1016/S0022-5223(03)00077-1
}
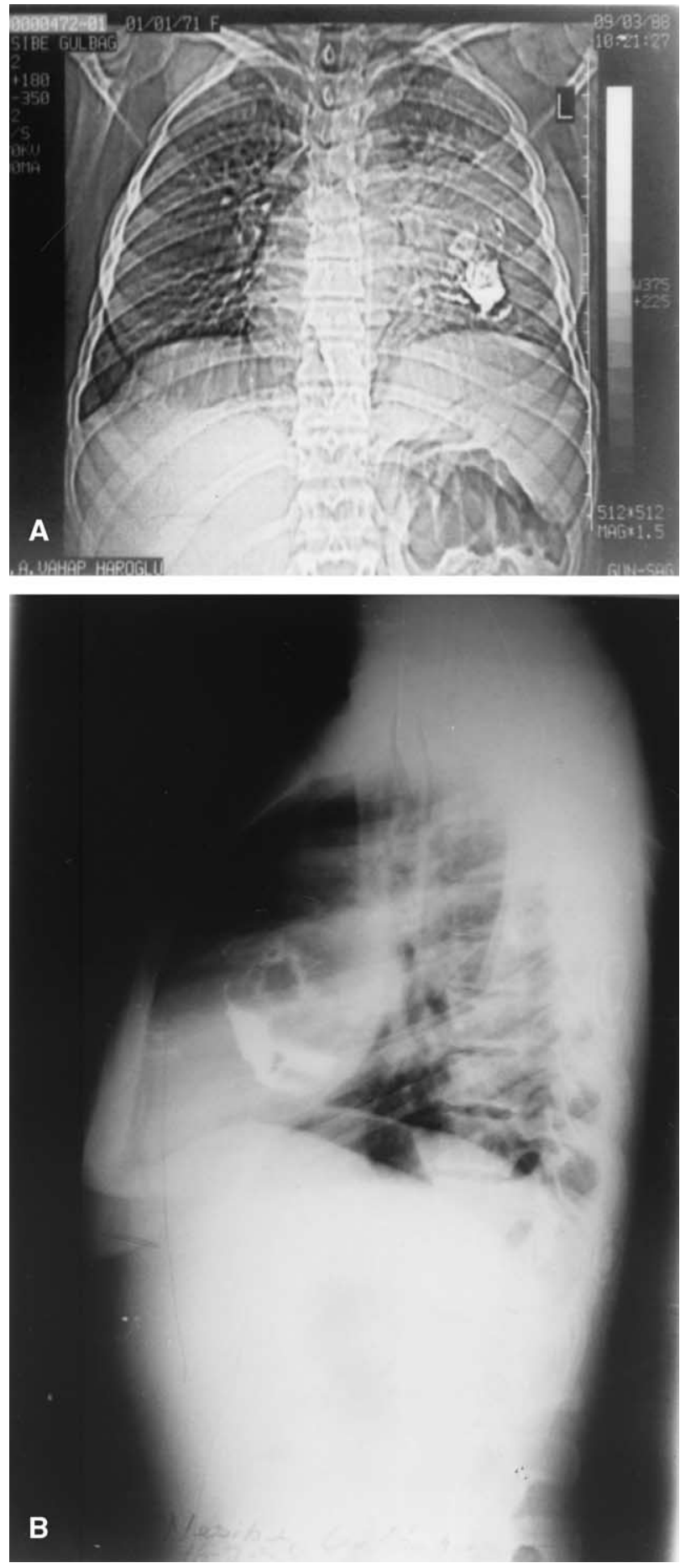

Figure 1. A, Tomographic image of the patient with pulmonary teratoma. B, Lateral chest radiograph of the patient. 


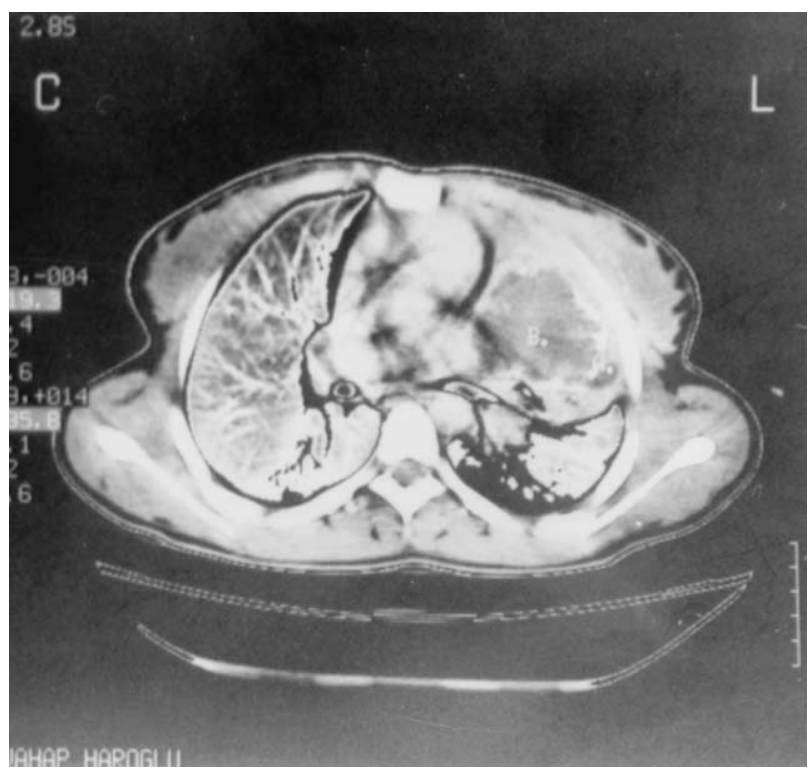

Figure 2. Computed tomographic image of the patient.

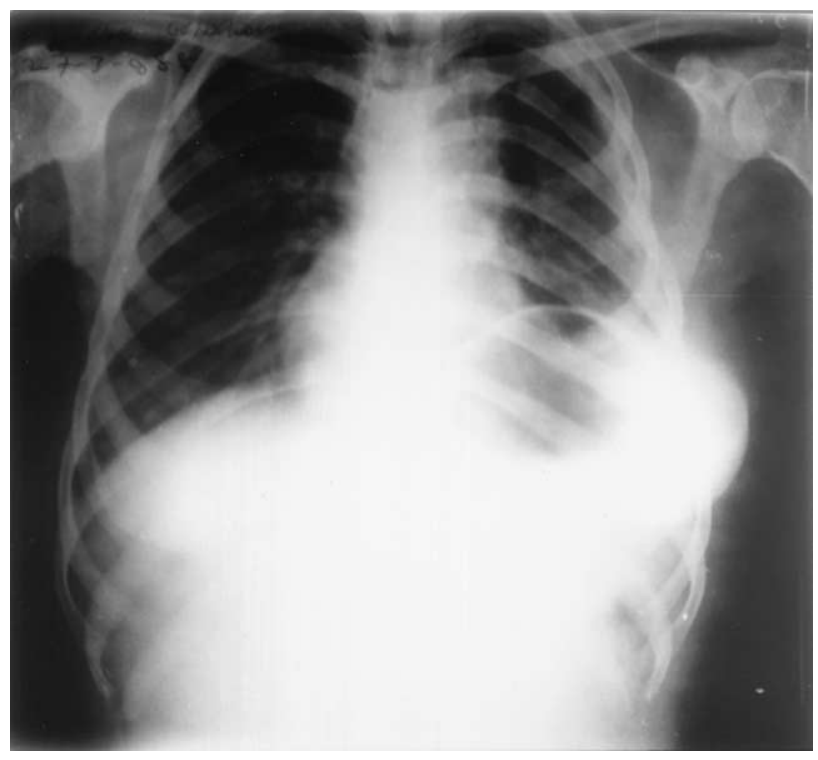

Figure 3. Postoperative chest radiograph of the patient.

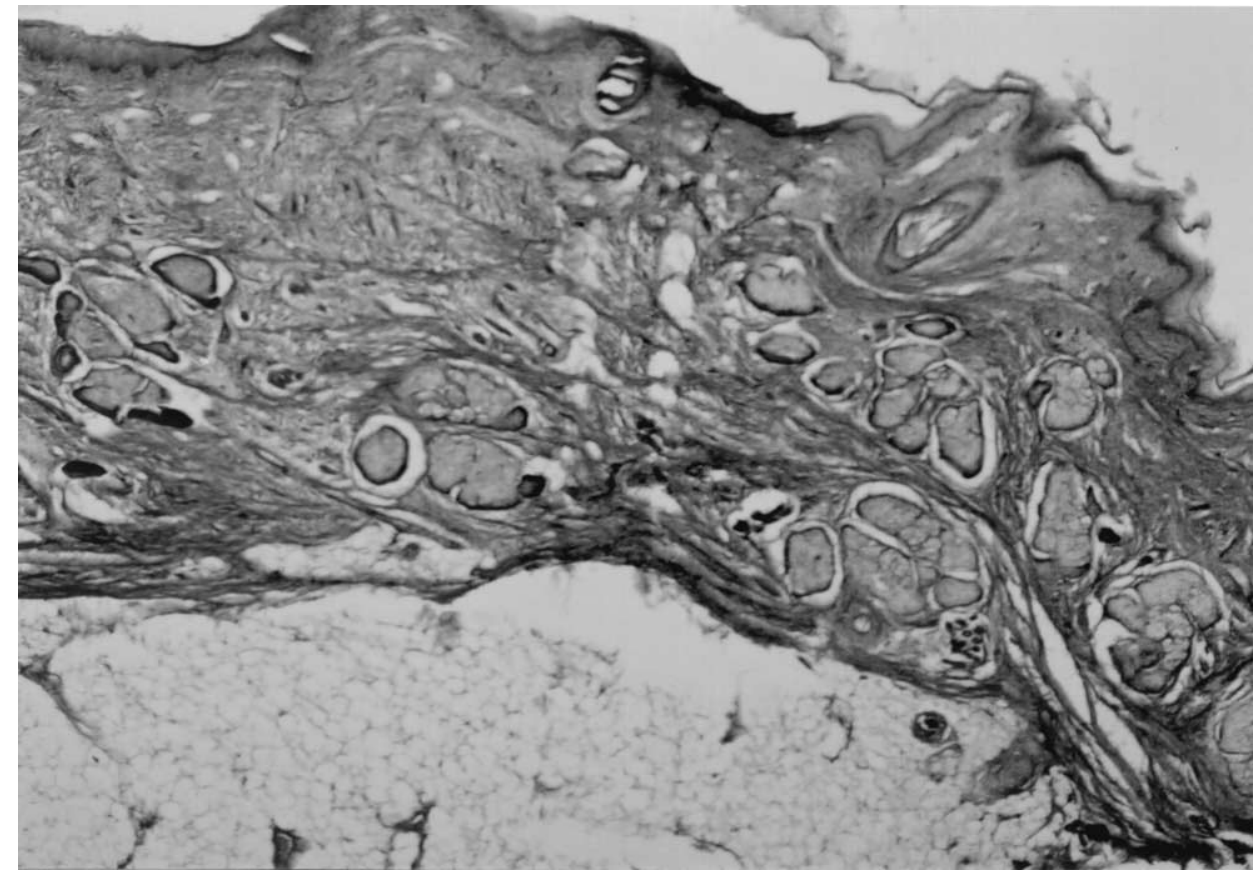

Figure 4. Microscopic view of the intrapulmonary teratoma.

The patient had an uneventful postoperative period. She has no complaint 16 years after the operation.

\section{Discussion}

Teratomas include different germinal layer derivations. Intrapulmonary teratomas are rare. They originate from a teratomatous focus in the mediastinum. Schlumberger ${ }^{1}$ stated that the association of endodermal components with intrathoracic teratomas stems from their origin in the third pharyngeal pouch and enlargement of the thymus.

According to 37 reports that we found, chest pain, cough, expectoration, and hemoptysis are the most commonly observed findings. A different finding, trichoptysis (hair expectoration), has been reported. ${ }^{2,3}$ There was no hemoptysis or hair expectoration in this case, which made preoperative diagnosis more difficult. This also indicates that there was no pathological communication with 
the bronchi. However, hair follicles were observed in the specimen of this case.

This kind of tumor is usually located in the left upper lobe, as in our case. Because of the presence of thymic tissue in some mediastinal and intrapulmonary teratomas, it has been speculated that these tumors might originate in the thymic tissue. However, the suggestion that early embryogenesis can cause separation or displacement of the thymus can be correct only for tumors found in the anterior mediastinum. The other explanation is that during the initial embryo period, a teratomatous focus in the mediastinum enters that tissue during respiratory growth and settles there. We have not encountered thymic tissue in histologic examinations. ${ }^{2-4}$

Intrapulmonary teratoma is treated by surgical resection. It has been reported that 5 of 18 patients in whom resection was performed died within 1 year. In addition, 4 patients died during the immediate postoperative period. Thus, this kind of tumor causes mortality and morbidity. ${ }^{2,5-7}$ Lobectomy was successful in our case.

\section{References}

1. Schlumberger HG. Teratoma of the anterior mediastinum in a group of military age. Arch Pathol. 1946;41:398.

2. Morgan DE, Sanders C, McElvein RB, et al. Intrapulmonary teratoma: a case report and review of the literature. J Thorac Imaging. 1992;3: 70-7.

3. Ustun MO, Demircan A, Paksoy N, et al. A case of intrapulmonary teratoma presenting with hair expectoration. Thorac Cardiovasc Surg. 1996;44:271-3.

4. Day DW, Taylor SA. An intrapulmonary teratoma associated with thymic tissue. Thorax. 1975;30:582-7.

5. Collier FC, Dowling EA, Plott DBS, Schneider H. Teratoma of the lung. AMA Arch Pathol. 1959;68:138-42.

6. Ali MY, Wong PK. Intrapulmonary teratoma. Thorax. 1964;19:228-35.

7. Trivedi SA, Mehta KN, Nanavaty JM. Teratoma of the lung: report of a case. Br J Dis Chest. 1966;60:156-9.

\title{
Video-assisted thoracoscopic resection for intralobar pulmonary sequestration: Single modality treatment with video-assisted thoracic surgery
}

\author{
James W. Klena, MD, ${ }^{\text {a }}$ Steven J. Danek, MD, FACP, FCCP, ${ }^{\mathrm{b}}$ Todd K. Bostwick, MD, ${ }^{\mathrm{c}}$ \\ Melissa Romero, CNP, and Joel A. Johnson, MD, FACS, ${ }^{a}$ Marquette, Mich
}

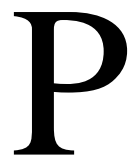

ulmonary sequestration is an uncommon congenital malformation of the foregut. Intralobar sequestrations are delineated by investment of the visceral pleura, lack of communication with the tracheobronchial tree, arterial supply from the aorta, and venous drainage to the left atrium through the pulmonary veins. The lesions usually present with recurrent pneumonia. Traditional management of these lesions has included arteriography to identify the systemic blood supply followed by thoracotomy and lobectomy to resect the sequestration. We report the successful treatment of intralobar pulmonary sequestration with video-assisted thoracoscopic surgery (VATS). VATS allows single modality treatment of intralobar sequestration with reduced morbidity compared with traditional management.

\footnotetext{
From the Departments of Cardiothoracic Surgery, ${ }^{a}$ Pulmonary Medicine, ${ }^{b}$ and Radiology, ${ }^{\mathrm{c}}$ Marquette General Hospital, Marquette, Mich.

Received for publication Dec 14, 2002; accepted for publication Jan 28, 2003.

Address for reprints: James W. Klena, MD, 528 Bishop Woods Road, Marquette, MI 49855 (E-mail: jwklena@yahoo.com).

J Thorac Cardiovasc Surg 2003;126:857-9

Copyright $\odot 2003$ by The American Association for Thoracic Surgery $0022-5223 / 2003 \$ 30.00+0$

doi:10.1016/S0022-5223(03)00364-7
}

\section{Clinical Summary}

A 34-year-old woman, previously in good health, was ad-

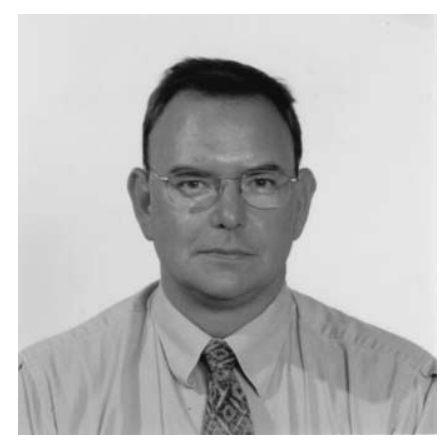

Dr Klena mitted to our institution with a 4-month history of recurrent right lower lobe pneumonia and hemoptysis. The chest $\mathrm{x}$-ray film revealed a persistent consolidation in the right lower lobe despite multiple courses of antimicrobial therapy. Bronchoscopic examination revealed blood in the right lower lobe bronchus but no other abnormalities. Cytology and culture results from the right lower lobe were negative. Spiral computed tomography (CT) of the thorax revealed a mass in the right lower lobe indicating a calcified aberrant blood vessel (Figure 1). The patient was referred to the cardiothoracic surgery service for definitive treatment. A VATS surgical exploration was planned.

The patient was placed in a left lateral decubitus position. A single-lumen endotracheal tube was used with a bronchial blocker placed in the right main-stem bronchus. A 10-mm, 0-degree thoracoscope was used through a port site placed in the seventh intercostal space on the midaxillary line. Two additional port sites were placed in the fifth intercostal space on the anterior and posterior axillary lines, respectively. Port sites were chosen to facilitate the completion of a right lower lobectomy. VATS exploration revealed an aberrant blood vessel emerging from the diaphragm entering the posterior basal segment of the right lower lobe (Figure 2). The affected segment was noted to be consolidated and could be grossly differentiated from the rest of the right lower lobe 